\title{
Frequent Episodic Vertigo Is an Unexpected Side Effect of Flutamide
}

\author{
Jiann-Jy Chen ${ }^{1,2}$, Dem-Lion Chen ${ }^{3 *}$ \\ ${ }^{1}$ Department of Medical Imaging, Taipei Medical University \& Shuang Ho Hospital, New Taipei, Chinese Taipei; ${ }^{2}$ Department of \\ Otorhinolaryngology, Tao-Yuan Hospital, Department of Health, Executive Yuan, Taoyuan, Chinese Taipei; ${ }^{3}$ G-Home Otorhi- \\ nolaryngologic Clinic, Kaohsiung, Chinese Taipei. \\ Email: jiannjy@yahoo.com.tw
}

Received April 28 $8^{\text {th }}$ 2011; revised May 28 ${ }^{\text {th }}, 2011$; accepted July $29^{\text {th }}, 2011$.

\begin{abstract}
An 82-year-old male suffered from prostatic cancer five years ago. Since then, he has taken flutamide and was bothered with episodic vertigo (EV) every morning. In order to treat prostatic cancer, flutamide was not discontinued, but conservative treatment and life-style change were recommended. Finally, EV actually subsided. Herein, we report the rare case, in which EV was an unexpected side effect of flutamide. Herein we review his whole history, physical examination, vestibular function test, electronystagmogram, caloric test, awake encephalogram, blood examinations, color-coded duplex ultrasonogram and magnetic resonance imaging/angiogram to suggest a mechanism of flutamide responsible for $E V$.
\end{abstract}

Keywords: Flutamide, Episodic Vertigo, Prostatic Cancer

\section{Introduction}

Flutamide (4'-nitro-3'-trifluoromethylisobutyranilide) could antagonize the nuclear androgen receptors of prostatic cancer, and inhibits intake of androgen; so, it has been widely applied to treat prostatic cancer. The main adverse reactions are reported diarrhea, nausea, vomiting, gastrointestinal distress, gynecomastia, muscular cramps and cardiovascular complications [1,2], and never episodic vertigo in the literature, but we encountered a case of frequent episodic vertigo after taking flutamide. Herein we report it because of rare curiosity and suggest a mchanism responsible for the side effect.

\section{Case Report}

A right-handed 82-year-old male has height $166 \mathrm{~cm}$, weight $55 \mathrm{~kg}$, and body mass index $20.0 \mathrm{~kg} / \mathrm{m}^{2}$. He did not suffer head trauma, hypertension, diabetes mellitus, heart disease, migraine or psychosis; neither did he have any hobby of cigarette smoking, alcohol drinking, areca chewing, or coffee consumption. However, he has regularly taken doxazosin (Doxaben) or terazosin (Hytrin) to treat benign prostatic hyperplasia for 12 years. Five years ago, he unfortunately got stage II prostatic adenocarcinoma and began taking anti-androgen flutamide (Fugerel) every day. Since then, he has bothered with episodic ver- tigo every early morning. Changing position exacerbated symptom, and only bed rest would relieve symptom in half an hour. There was no headache, blurred vision, ataxia, syncope, tinnitus, hearing block or other neurologic signs.

Three years ago, he first visited our emergency due to sever episodic vertigo with nausea and vomiting. Blood pressure (heart rate) was $122 / 78 \mathrm{mmHg}(59 / \mathrm{min})$. One hour after he was treated conservatively, symptoms subsided, and blood pressure (heart rate) was $142 / 89 \mathrm{mmHg}$ (86/min). Then, Doxazosin or Terazosin was discontinued, but episodic vertigo still recurred every early morning. Last July, he visited our emergency again. Blood pressure (heart rate) was $128 / 79 \mathrm{mmHg}(47 / \mathrm{min})$. When symptoms subsided, blood pressure (heart rate) rose to $138 / 89 \mathrm{mmHg}(72 / \mathrm{min})$. Computed tomography of brain was unremarkable. In the following three days, he was assigned to the author for a battery of studies.

Physical examination and vestibular function test were normal, except that squat to stand test or hyperventilation test provoked the same vertigo. Electronystagmogram, caloric test, awake encephalogram and blood examinations were unremarkable. Color-coded duplex ultrasonogram (EnVisor, Philips, USA) revealed mild atherosclerosis over bilateral common carotid arteries, and total 
cerebral flow volume was $760 \mathrm{~mL} / \mathrm{min}$, which was the sum of bilateral internal carotid arterial volumes and bilateral vertebral arterial volumes (Table 1). Twenty-four hours' Holter showed that heart rate was averaged 68 beats/min with highest 114 beats/min (8:00 am) and lowest 42 beats/min (4:00 AM). T1, T2, fluid-attenuated inversion recovery and diffusion weighted image magnetic resonance imaging (1.5 Tesla system, Picker Edge Eclipse, Picker 98 International, USA) did not find any lesion, but time of flight magnetic resonance angiogram (TOF MRA)(TR/TE/excitation: 29/6/1) showed central vascular anomalies: 1) posterior incomplete circle of Willis (Figure 1(a)) and 2) tortuous vertebrobasilar artery (Figure 1(b)).

In order to suppress prostatic cancer, flutamide was not discontinued, so he was conservatively treated with diphenidol (Cephadol), ginkgo flavone (Jinbo), and aspirin (Bokey); besides, he was asked to slow down getting up or changing position in early morning. One week later, symptom did not recur any more. In the following half a year, it was uneventful although he did not take diphenidol, ginkgo flavone, and aspirin any more.

\section{Discussion}

He has been bothered with episodic vertigo every early morning for five years. Doxazosin or terazosin, longacting selective $\alpha 1$-antagonist, is known to treat benign prostatic hyperplasia and hypertension by relaxing smooth muscle of vessels, urinary bladder and prostate; however, it could induce dizziness (vertigo), fatigue, hypotension, edema and dyspnea via the same mechanism $[3,4]$. $\alpha 1$-antagonists have been discontinued after $1^{\text {st }}$-time emergency, but symptom did not relieve any more; thus, symptom was by far not a side effect of $\alpha 1$-antagonist. Symptom always subsided after heart rate and blood pressure have risen in these two emergencies; besides, squat to stand test and hyperventilation test induced the same symptom; thus, symptom was associated with cardiovascular dysfunction and central nervous hemodynamic instability although 24-hour electrocardiogram was normal.

Seventy four point six percent of 18 - 89 year-old Taiwanese have defects of posterior circle of Willis, and among them, $57.4 \%$ are short of bilateral posterior communicating arteries (Figure 1(a)) [5], and communication of anterior and posterior circulation must be limited [6]. It is probable that vertebrobasilar arterial system degenerated abnormally in the $5^{\text {th }}$ embryologic week, and resulted in bilateral intracranial vertebral artery tortuosity. After birth, asymmetric blood flows of vertebral artery gradually bended basilar artery year by year (Figure 1(b)) [7]. Finally, tortuous vertebrobasilar artery might become locally more thrombogenic secondary to vascular resis-
Table 1. Color-coded duplex ultrasonogram of extracranial vertebral arteries.

\begin{tabular}{ccccc}
\hline & $\begin{array}{c}\text { Diameter } \\
(\mathrm{mm})\end{array}$ & $\begin{array}{c}\text { Average velocity } \\
(\mathrm{cm} / \mathrm{sec})\end{array}$ & $\begin{array}{c}\text { Average flow } \\
(\mathrm{ml} / \mathrm{min})\end{array}$ & $\begin{array}{c}\text { Resistance } \\
\text { index }\end{array}$ \\
\hline Right & 3.09 & 14.9 & 67 & 0.69 \\
Left & 3.68 & 16.3 & 104 & 0.65 \\
\hline
\end{tabular}
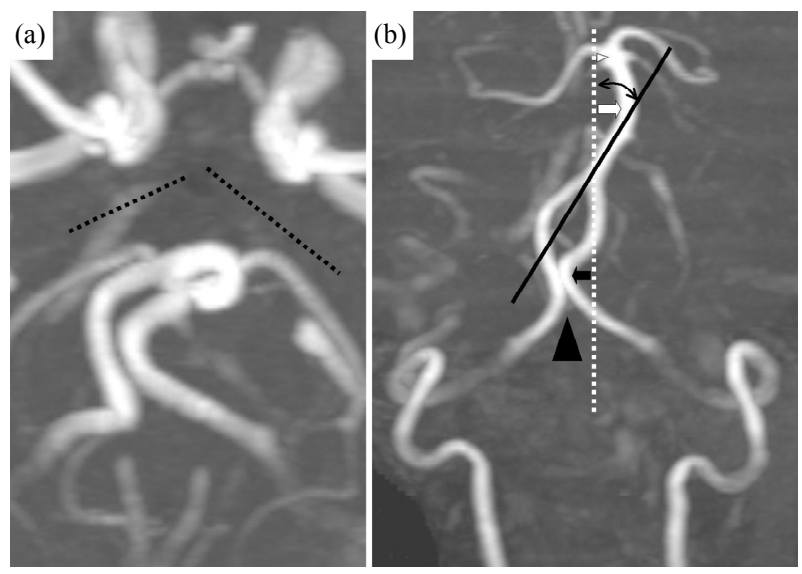

Figure 1. (a) TOF MRA showed dislinkage of anterior and posterior circulation (dotted lines) due to absence of bilateral posterior communicating arteries; (b) the axis of vertebrobasilar artery (black line) rotated clockwise (double-headed curved arrow). The upper extreme and middle of basilar artery (diameter $4.0 \mathrm{~mm}$ ) were respectively 2.9 mm (hollow arrow head) and $5.1 \mathrm{~mm}$ (hollow arrow) apart from mid-line (white spotted line). Before connecting basilar artery, right vertebral artery (diameter $2.0 \mathrm{~mm}$ ) formed a sigmoid route, and so did left vertebral artery (diameter $3.8 \mathrm{~mm}$ ) a crooked route. The rightward extreme of left vertebral artery was $4.5 \mathrm{~mm}$ (filled arrow) apart from midline (white spotted line), and approximated to right vertebral artery (filled arrow head).

tance. Therefore, these central vascular anomalies might incur vertebrobasilar artery insufficiency at specific condition although neck duplex scanning was unremarkable (Table 1).

Androgen is known to not only keep artery or arteriole sensitive to baroreflex [8], but also provoke the pathway of nitrogen-monoxide genesis in central nervous system, activating angiotensin II system and raising blood pressure [9]. After he has had to regularly take Flutamide to suppress prostatic cancer, Flutamide has antagonized androgen receptors of central nervous system, heart, and peripheral arterioles; so, regulation of blood pressure and heart rate were limited.

Sudden getting up or changing position could incur transient vertebrobasilar artery insufficiency secondary to postural hypotension, especially during low sympathetic tone in early morning. We suggest that not only age, but also Flutamide has limited the immediate compensation 
of heart rate and blood pressure for transient vertebrobasilar artery insufficiency; fortunately, simply episodic vertigo resulted, but not ischemia stroke. However, it was beyond neck duplex scanning to identify transient vertebrobasilar insufficiency; besides, it was beyond electronystagmogram and caloric test to identify transient vestibulopathy.

In order to suppress prostatic cancer, Flutamide was not discontinued, and conservative treatment and life-style change were recommended as below. Diphenidol has been tried to relieve vertigo. Ginkgo flavone and aspirin have also been tried to decrease the vascular resistance of vertebrobasilar artery. In order to spare his heart enough time to compensate for postural hypotension, he was asked to slow down getting up or changing position. As a result, episodic vertigo did not recur in one week despite daily flutamide. In the following over half a year, it was uneventful although he has not taken diphenidol, ginkgo flavone and aspirin any more. Herein, we report the case, in which EV was an unexpected side effect of flutamide.

\section{REFERENCES}

[1] D. G. McLeod, “Antiandrogenic Drugs," Cancer, Vol. 71, No. 3, 1993, pp. 1046-1049. doi:10.1002/1097-0142(19930201)71:3+<1046::AID-CN CR2820711424>3.0.CO;2-M

[2] E. J. Dole and M. T. Holdsworth, "Flutamide: An Antiandrogen for the Treatment of Prostate Cancer," The Annals of Pharmacotherapy, Vol. 31, No. 1, 1997, pp. 65-75.

[3] H. Lepor, "Alpha Blockers for the Treatment of Benign Prostatic Hyperplasia," Reviews in Urology, Vol. 9, No. 4,
2007, pp. 181-190.

[4] R. Kirby and A. Jardin, "Doxazosin in the Treatment of Benign Prostatic Hyperplasia. A Review of the Safety Profile in Older Patients," Prostate Cancer and Prostatic Diseases, Vol. 1, No. 2, 1997, pp. 84-89. doi:10.1038/sj.pcan.4500211

[5] H. W. Chen, P. S. Yen, C. C. Lee, C. C. Chen, P. Y. Chang, S. K. Lee, W. H. Lee, C. M. Ling and A. S. B. Chou, "Magnetic Resonance Angiographic Evaluation of Circle of Willis in General Population: A Morphologic Study in 507 Cases," Chinese Journal of Radiology, Vol. 29, No. 5, 2004, pp. 223-229.

[6] D. F. Schomer, M. P. Marks, G. K. Steinberg, I. M. Johnstone, D. B. Boothroyd, M. R. Ross, N. J. Pelc and D. R. Enzmann, "The Anatomy of the Posterior Communicating Artery as a Risk Factor for Ischemic Cerebral Infarction," The New England Journal of Medicine, Vol. 330, No. 22, 1994, pp. 1565-1570. doi:10.1056/NEJM199406023302204

[7] J. M. Hong, C. S. Chung, O. Y. Bang, I. S. Joo and K. Huh, "Vertebral Artery Dominance Contributes to Basilar Artery Curvature and Peri-Vertebrobasilar Junctional Infarcts," Journal of Neurology, Neurosurgery \& Psychiatry, Vol. 80, No. 10, 2009, pp. 1087-1092. doi:10.1136/jnnp.2008.169805

[8] G. R. Ward and A. A. Abdel-Rahman, "Orchiectomy or Androgen Receptor Blockade Attenuates Baroreflex-Mediated Bradycardia in Conscious Rats," BMC Pharmacology, Vol. 6, 2006, p. 2. doi:10.1186/1471-2210-6-2

[9] B. Xue, A. K. Johnson and M. Hay, "Sex Differences in Angiotensin II-Induced Hypertension," Brazilian Journal of Medical and Biological Research, Vol. 40, No. 5, 2007, pp. 727-734. doi:10.1590/S0100-879X2006005000093 